\title{
La esencia de la técnica en Heidegger
}

\author{
Miguel Ángel Polo Santillán \\ Departamento Académico de Filosofia
}

Al Dr. Antonio Peña Cabrera,
maestro sanmarquino

\section{Intraducción}

En pocos meses, la tecnociencia hará posible la clonación de un ser humano. Los gobiernos occidentales lo habian prohibido en sus respectivos paises, pero dado el dominio del poder económico y tecnológico, siempre será posible encontrar un cientifico y un empresario que deseen realizarla. Aunque muchos estarán en desacuerdo, lo cierto es que hay una fuerza que impulsa a seguir por ese camino abierto por la bioingeniería. Desde nuestros espacios, necesitamos volver a pensar serenamente sobre este fenómeno que nos envuelve, a pesar de vivir al margen de la modernidad. ¿Cómo es que la tecnociencia está posibilitando estos medios tecnológicos? ¿Cuál es el sentido de todo este proceso? ¿Cuál es la esencia misma de la técrica? Creo què unā de las más interesantes aproxjmaciones a este problema lo ha ofrecido Heidegger quien, viendo los límites de otras aproximaciones, nos muestra la esencia de la técnica moderna. El objetivo de nuestro artículo es revisar los argumentos heodeggerianos y ver su trascendencia.

\section{Metafisica y técnica}

Uno de los tópicos centrales del pensamiento de Heidegger es el estudio del pensamiento metafisico occidental como olvido de la pregunta esencial: la pregunta por el sentido del ser. Ha sostenido que el pensar metafisico empezó con Platón y llega hasta su consumación con Nietzsche. Platón olvidó el ser porque fundamentó al ser en la ldea, convirtiendo el pensar en pensar técnico. Con la metafisica cristiana Dios se convierte en el ente Supremo y por último la metafisica moderna (caracterizada por el subjetivismo) va a permitir el conocimiento objetivo con lo cual el hombre modemo se dispone a dominar el mundo. Así, la tecnociencia es expresión de la historia de la metafísica y no superación 
de la metafísica. La ciencia supone una teoría de la realidad, una metafísica, que entiende lo real como aquello que puede ser medido, como lo objetivo construido por el sujeto. De esa manera, el pensar tecno-cientifico es resultado de la metafisica occidental que ha olvidado al ser.

La vuelta a la pregunta por el sentido del ser supone la superación de la metafísica, superación que no significa eliminar la metafísica, sino una mirada a sus fundamentos que la han hecho posible.

La metafisica sigue siendo lo primero de la filosofia. Nunca llega a ser lo primero del pensar. En el pensamiento sobre la verdad del ser, la metafisica se ve superada...Pero esta "superación de la metafísica" no margina a la metafísica. Mientras el hombre siga siendo un animal rationale, también es el animal mataphysicum. Mientras el hombre se comprenda como ser vivo racional, de acuerdo con la expresión de Kant, la metafisica seguirá formando parte de la naturaleza de hombre. Ahora bien, lo que sí es posible es que si algún día el pensar consigue retornar al fundamento de la metafisica ocasione un cambio en la esencia del hombre que llevaria aparejada una metamorfosis de la metafisica. (Heidegger: 2001,301)

La superación del pensar metafísico requiere partir del origen, pensar en la esencia del ser mismo dondecel ser se hace presentey esto no es posible sino como "evento" (Ereignis), Así, Heideggecpiensa ebser como un evento y no como un «ente» o «super-ente». El evento es el acto de acaecer, lo cual traza su destino. La superación de la metafísica debe darse desde el evento. Además, el desvelamiento del ser no puede darse ni en el lenguaje científico ni en el lenguaje ordinario, que sólo se dirigen a los entes y no al ser. Cree Heidegger que la tarea es una "vuelta" (Kehre) a nuevas formas de desvelamiento, como por ejemplo sucede en la poesia. Es el lenguaje de la poesía la que puede acercarnos al ser:

El lenguaje es la casa del ser. En su vivienda mora el hombre. Los pensadores y poetas son los vigilantes de esta vivienda. (Heidegger: 1970, 7)

El lenguaje poético como medio de desvelamiento del ser para superar la metafísica. Así el hombre se convierte en el pastor del ser, no en su dueño. Este pensar original lo encuentra Heidegger en los prosocráticos, quienes pensaron el ser desde el ser mismo. Pero ese desvelamiento (aletheia, término griego para 
verdad) del ser ya forma parte d la historia del ser, mas la forma del desvelamiento actual tiene que ver con otros sucesos en el cual cambia la forma como el hombre se entiende a sí mismo y transforma su imagen de lo real.

\section{El sujeto metafisico moderno}

En su obra Ser y Tiempo, Heidegger ha criticado el conocimiento entendiendo como una relación entre sujeto y objeto, ontológicamento separados uno del otro, pero sin dar cuenta suficientemente de la trascendencia que implica conocer. Entender el fenómeno del conocimiento como una relación entre sujeto y objeto, contiene tanta «verdad» como vacuidad. ¿En qué consiste la «verdad» y la vacuidad de esta concepción tradicional del conocimiento?

«Sujeto» y «objeto» no corresponden con los términos «ser ahi» (hombre) $\mathrm{y}$ «mundo». ¿Por qué el sujeto no corresponde con el «ser ahí»?. En el parágrafo 10 de esta obra escribe:

Toda idea de un "sujeto» - a menos que sea depurada por medio de una previa determinación ontológica fundamental- lleva ontológicamente consigo la posición de un subjectum (hypokeimenon), por mucho que ónticamente uno se ponga en guardia frente a una "una sustancia del alma» o a una "eosificación de la conciencia». (Heidegger: 1962. Parágrafo 10) "Jorge Puccinelli Converso"

Así, la idea de «sujeto» supone el subjectum, lo que está debajo, lo que subyace. Que para los premodernos tenia una significación de fundamento de la realidad, pero con Descartes se identifica con el hombre. Nos dice Heidegger al respecto en "La época de la imagen del mundo»:

Pero cuando el hombre pasa a ser el sujeto primero y propiamente dicho, eso significa: El hombre pasa a ser aquel existente en el cual se funda todo lo existente a la manera de su ser y de su verdad. El hombre se convierte en medio de referencia de lo existente como tal. Pero eso sólo es posible si se transforma la concepción de lo existente en conjunto. (Heidegger: 1960,78).

Un sujeto de conocimiento supone algo que subyace al conocer, una sustancia pensante cartesiana que conoce un mundo que no es pensante. El sujeto 
de conocimiento supone una conciencia encerrada, una conciencia que se entiende sólo a partir de sí misma que de algún modo «misterioso» tenía que trascender para conocer esa realidad distinta sustancialmente de sí.

¿Y por qué el «objeto» no corresponde al mundo? El hombre, como sujeto pensante, es entendido desde la modernidad como sujeto que representa el mundo y al hacerlo lo pone frente a sí. Objeto significa lo que se pone en frente, que no es otra cosa lo que el hombre representa. Al respecto anota Heidegger:

Lo existente ya no es lo presente, sino lo que por vez primera en el representar se pone enfrente, lo ob-jético. Representar es una objetización que procede, que domina. (Heidegger: 1960, 95).

Esa representación es lo que constituye lo real, como dirá luego, provocando la naturaleza. Asi la ciencia pasa a ser una "teoría de lo real", donde sólo un modo de develamiento del ser cuenta, el modo tecnocientífico. Mientras que para el griego lo real es lo que presenta, tanto por la acción humana como por la acción de la naturaleza, para el moderno lo real es lo que representa, convirtiéndose él mismo en fundamento de todo lo existente, es decir en sujeto.

Sin embargo, el mundo, en el cual el hombre es, no es un objeto, lo que está frente a uno, sino es un elemento constitutivo del ser-ahí. Entonces, si el ser-en-elmundo es una constitución fundamental dèlser-ahí, esto significa que el conocimiento es un modo de ser del ser-ahi, del ser humano. El conocimiento sólo es posible porque al ser humano ya le es constitutivo estar en el mundo. De esta manera, supera Heidegger la supuesta contraposición entre sujeto-objeto en el conocimiento. Frente al sujeto moderno, Heidegger afirma que el que conoce, el ser-ahí, ya es un ser-en-el-mundo, es decir, un ser trascendente. El Dasein, serahi, tiene como una estrucctura fundamental el ser-en-el-mundo. El conocimiento es modo de ser del Dasein.

\section{La pregunta por la técnica}

Sobre la base de los dos temas desrrollados brevemente es que podemos entender un poco mejor sus reflexiones sobre la técnica. Para ello nos serviremos de su obra La pregunta por la técnica (Die Frage nach der Technik, 1954). Heidegger empieza su reflexión distinguiendo la determinación correcta de la técnica de la interpretación verdadera de la técnica. La primera considera a la 
técnica como un medio para un fin y como un hacer del hombre. Esta concepción de la técnica la denomina una "concepción instrumental y antropológica", que es correcta ("desazonadoramente correcta")pero no ve la esencia de la técnica, por lo que no llega a ser plenamente verdadera. Entender a la técnica como simple instrumento neutral para fines que el hombre se plantee (concepción instrumental) o entender la técnica como un hacer del hombre (concepción antropológica) son perspectivas limitadas en tanto que no nos permiten ver la esencia misma de la técnica. Y sobre esas perspectivas es que muchos téricos han venido y siguen pensando la tecnociencia.

En cambio, la interpretación verdadera se atiene a la esencia de la técnica, lo cual no es algo técnico. Utilizando un procedimiento aparentemente tradicional nos dice:

Si nosotros buscásemos la esencia del árbol, tendriamos que elegir aquello que domina a través de todo árbol en cuanto árbol, sin ser ello mismo un árbol, que se pudiera encontrar entre los restantes árboles. Ast también, la esencia de la téenica no es, en absoluto, algotécnico. (Heidegger: 1993,71).

Decimos aparentemente porque la esencia de la cual habla Heidegger no es algo etemo en sentido platónico, sino algo histórico. En otras palabras, la esencia de la técnica hay que verla desde la historia del ser. Clave interpretativa del pensamiento de Heidegger. Constantemente, elfilósofo alemán va a sostener que la técnica no es igual a la esencia de la técnica Ver lo técnico como tal y, además, como algo neutral nos vuelve "ciegos" para la esencia de la técnica, problema muy frecuente entre los tecnócratas de toda especialidad, podríamos affadir, que suelen entender la ciencia sólo a partir de criterios técnicos, dejando de lado el contexto cultural que la ha posibilitado.

\section{La técnica como desocultamiento}

La consideración de la técnica como instrumento (instrumentum), le lleva a Heidegger hasta el concepto de "causa" desde la perspectiva griega. El filosofo entiende a las cuatro causas aristotélicas como modos de ser-responsable-del aparecer y la presencia del ser. Y el pro-venir a la presencia es producir, que en griego es poieseis. 
Pro-ducir, poiesis, es no sólo la hechura artesana, no sólo es traer a forma y figura artístico-poético. La physis incluso es poiesis en el más elevado sentido. Pues lo presente physei tiene en sí mismo el brotar en el pro-ducir, por ejemplo, el brotar de las flores en el florecer. Por el contrario, lo pro-ducido artesana y artísticamente, por ejemplo,la copa de plata, tiene el brotar en el pro-ducir no en sí mismo, sino en otro, en el artesano y en el artista.(Heidegger: 1993,78)

Así, las cuatro causas como modos de dar-lugar-a se dan dentro del producir, sean para las cosas naturales como humanas. Este producir produce desde el velamiento al desvelamiento, es decir, al des-ocultamiento (alétheia). Heidegger conecta la pregunta por la técnica con la verdad, que en sentido griego es desvelamiento y lo fundamenta de la siguiente manera:

En el desocultar se funda todo pro-ducir. Pero éste reúne en sí los cuatro modos del dar-lugar-a-la causalidad-y los domina. A su ámbito pertenecen fin y medio, pertenece lo instrumental. Este vale como el rasgo fundamental de la téenica.... En él descansa la posibilidad de toda fabricaciôn productora. (Heidegger: 1993, 79).

Toda técnica, antigua y moderna, son modos del desocultamiento (verdad), de "salir de lo oculto". Âsi, la pregunta por la técnica lleva a Heidegger a descubrir que el "rasgo fundamental" de ésta es el desocultar, lo cual le servirá como hilo interpretativo. Porêfo, llega a la conefusión que la esencia de la técnica no se reducéalogmstrumèntal queopuédeser usado y dominado por el hombre:

La técnica no es, pues, simplemente un medio. La técnica es un modo de desocultar. Si prestamos atención a eso, entonces se nos abriría un ámbito distinto para la esencia de la técnica. Es el ámbito del desocultamiento, esto es, de la verdad. (Heidegger: 1993, 79).

De esa forma, desenmascara la concepción corriente que la técnica es simplemente un medio y de ahí instrumento para el hacer humano. Luego pasa a analizar el origen griego de la palabra técnica, tekné, donde hace dos observaciones: a) téchne no mienta sólo el hacer y saber del artesano sino también el arte, las bellas artes. Y la téchne pertenece al pro-ducir, a la poiesis. Por eso sostiene que la téchne es algo poético. b) La palabra griega téchne está unida desde el comienzo con la episteme, ambos son palabras para conocer que como 
tal es un desocultar. $\mathrm{Y}$ vuelve a sostener que lo decisivo de la técnica es el desocultar.

La técnica es un modo de desocultar. La técnica presencia en el ámbito en el que acontece desocultar y desvelamiento, alétheia, verdad. (Heidegger: 1993, 80).

\section{La técnica moderna como pro-vocación}

Pero no sólo la técnica en sentido griego, sino también la técnica moderna es un modo de desocultar, con una diferencia importante: la técnica moderna no se da en el ámbito del pro-ducir sino en el ámbito del pro-vocar. Esta forma de entender la verdad desde la técnica es de manera provocante. En un párrafo sumamente sugerente nos dice:

Ahora bien, el desocultar que domina a la técnica moderna no se despliega en un pro-ducir en el sentido de poiesis. El desocultar imperante en la técnica moderna es un provocar que pone a la naturaleza en la exigencia de liberar energias, que en cuanto tales puedan ser explotadas y acumuladas. Pero, ¿no vale eso también para el viejo molino de viento? No. Sus aspas giran, ciertamente, en el viento, a cuyo soplar quedan inmediatamente entregadas. Pero el molino de viento no abre las energías de las corrientes de aire para acacumularlas.

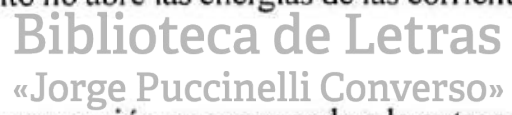

Por el contrario, una región es provocada a la extracción del carbón y minerales. La tierra se desoculta ahora como región carbonífera, el suelo como lugar de yacimiento de minerales. De otra manera aparece el campo, que el campo antiguamente labraba, en donde labrar aún quiere decir: cuidar y cultivar. El hacer del campesino no provoca al campo. En el sembrar las simientes, abandona él la siembra a las fuerzas del crecimiento y cuida su germinación. Entretanto, la labranza del campo... La pone en el sentido de provocación. El campo es ahora industria motorizada de la alimentación. El aire es puesto dentro de la entrega de nitrógeno, el suelo por los minerales; minerales, por ejemplo, el uranio, éste por la energía atómica, que puede ser desintegrada para construcción o para usos pacíficos. (Heidiegger: 1993, 81-82. Cursivas mias). 
Así, la naturaleza se convierte en una fuente de servicio para la técnica y la industria moderna. El desocultar de la técnica moderna es un poner que provoca y exige la utilización mayor con el mínimo esfuerzo. De ese modo, quiere desocultar las energías ocultas en la naturaleza. Lo desocultado es transformado, acumulado, repartido y cambiado, todos los cuales vienen a ser modos del desocultar de la técnica moderna. Además, esta técnica hace que la naturaleza se presente como Bestand, como algo constante, ya no como objeto (Gegenstand).

Si bien es cierto que el hombre realiza este poner pro-vocante de la técnica moderna, sin embargo, el hombre no dispone sobre el desvelamiento, sólo puede concebir, formar e impulsar, esto o aquello, de una manera o de otra. La razón es que el hombre ya está establecido y provocado dentro de un desvelamiento que no depende de él.

Cuando el hombre, asu manera, dentro del desvelamiento, desoculta lo presente, entonces él no hace sino corresponder a la llamada del desvelamiento, aun cuando la contradiga. (Heidegger: 1993, 86).

El hombre moderno queda atrapado con lo desocultado, entusiasmado por el progreso no observaque ese desvelamiento es uno entre otros posibles, cerrándose a esas otras formas de desvelamiento. El desocultamiento tiende a regir nuestras vidas, sea que estemos a favor o en contra.

\section{Biblioteca de Letras Ge-stell como esenciadola técnicampderna verso"}

La técnica moderna no es pues un simple hacer humano, sino es un desocultar estableciente que provoca y hace que el hombre asuma lo real como constante. A esa interpelación provocante la denomina lo dispuesto (das Gestell). Es a lo dis-puesto lo que denomina la esencia de la técnica moderna. Heidegger lo interpreta así:

Dis-puesto significa lo reunidor de aquel poder, que pone al hombre, esto es, lo pro-voca, a desocultar lo real en el modo del establecer en cuanto lo constant. Dis-puesto significa el modo del desocultar que impera en la esencia de la técnica moderna y que él mismo no es nada técnico. (Heidegger: 1993, 88).

Gestell convierte a la naturaleza, a lo real, en un almacén de existencias (Moya: 1998, 60). La técnica moderna permite que la naturaleza (y el hombre 
mismo después de todo, como está sucediendo en la biotecnología) esté a disposición del hombre, en ello radica su esencia. A pesar de la voz de alerta del ecologismo al decirnos que los recursos naturales se agotan, la esencia de la técnica sigue operando de la misma manera.

"La esencia de la técnica no es nada técnico" quiere decir que siendo expresión de la historia de la metfísica como olvido del ser, su verdadera comprensión no puede acontecer desde el obrar técnico producto de esa historia. Y más adelante:

En lo dispuesto acontence apropiadamente el desvelamiento, conforme al cual el trabajo de la técnica moderna desoculta lo real como constante (Heidegger: 1993, 89).

El modo moderno de acceder al desvelamiento es mediante "lo dispuesto" se muestra en los productos (dispuestos) que la industrialización y la tecnociencia han hecho posible para no entrar en contacto con el actuar de la naturaleza. Esto también lleva a pensar a Heidegger que la fisica experimental surge desde lo dispuesto, es decir, desde una forma previa de entender la naturaleza como "conexión de fuerzas calculables".

La física moderna no es fisica experimental porque en sus pesquisas acerca de la naturaleza aplique aparatos, sino que, inversamente: porque la fisica, y pori cierte, como pura tẹoria; pone a la naturaleza como lo que hay que concebir en cuanto conexión de fuerzas, previamente calculable, es por lo que se establece el experimento; esto es, para indagación de si la naturaleza, puesta de esa manera, anunciará y cómo lo hará. (Heidegger: 1993, 89).

Física moderna precursora de lo dispuesto como "reunir provocante en el desocultar establecedor", que prepara el camino tanto a la técnica como a la esencia de la técnica moderna. Y como la esencia de la técnica moderna es lo dis-puesto, ello hace que tenga que aplicar la ciencia natural exacta. De ese modo no permite que el ser se haga presente, sino que sea resultado de una medición matemática. De ese modo el ser pasa a ser lo objetivo (Gegen-stand), objeto que está frente al sujeto. 


\section{EL destino de la técnica}

Y como la esencia de la técnica lleva al hombre por un camino, Heidegger denomina a esto (Geshick) que no la entiende por fatalidad.

El desvelamiento de lo que es, siempre va sobre un camino de dosocultar. Siempre impera al hombre el destino del desocultamiento. Pero no es jamás la fatalidad de una coacción. Pues, precisamente el hombre llega a ser libre en tanto que pertenece al ámbito del destino y así, llega a ser un oyente, no un esclavo. (Heidegger: 1993, 93).

Así, esta forma de desocultar de la técnica no es la definitiva, por lo que tenemos posibilidades de nuevos desvelamientos más auténticos. Lejos de contraponer libertad y destino, nos dice que la libertad es el "ámbito del destino". Y el destino de la esencia de la técnica moderna puede llevarnos o a identificar todo con lo desocultado en el establecer o a experimentar la pertenencia al desocultar. Esto hace decir a Heidegger que el destino del hombre está en peligro. Lo dis-puesto vela tanto lo pro-ducir (poiesis) como la verdad misma.

Lo dis-puesto disloca (verstellen) el aparecer y dominar de la verdad. ...Lo peligroso no es la técnica. No hay ningún demonio de la técnica, sino, por el contrario, el misterio de su esencia. La esencia de la técnica es, ểncưantođun destino det desecultar, el peligro. La amenaza no lexieneal hembre principalmente de que las máquinas y aparatos de la técnica puedan actuar quizás de modo mortífero. La más peculiar amenaza se ha introducido ya en la esencia del hombre. El dominio de lo dis-puesto amenaza con la posibilidad de que el hombre pueda rehusarse a retrotraerse a un desocultar más originario y asi negarse a experimentar el aliento (Zusprucch $=$ llamada) de una verdad más inicial. (Heidegger: 1993, 97. Cursivas mías.)

La esencia de la técnica puede cegarnos a nuevos desvelamientos del ser, he ahi el peligro. La tecnociencia se ha vuelto un desocultar arrogante que no permite otros modos de desocultamiento ( no descubrimientos al modo tecnocientifico), para Heidegger "más originales". ¿Cuáles serían? Aunque Heidegger a señalado al lenguaje poético, ello tiene que ver también con formas mitológicas y religiosas de ver y sentir la naturaleza. ¿Será por ello que las llamadas postmodernas al despliegue de la experiencia individual buscan ser modos alternativos de 
desvelamientos? Sin embargo, en tanto no sean formas de escapar del destino, en tanto que no sea un simple oponerse a la tecnociencia, sino como "superación de la metafisica moderna" es que dichos desvelamientos pueden ser originarios.

Pero recordando a Hölderlin nos dice que "donde hay peligro crece también lo salvador". Y buscar lo salvados de la esencia de la técnica lo lleva a meditar una vez más sobre la esencia, encontrando que ella se refiere al perdurar y confiar. $\mathrm{Y}$ aunque el desocultar pro-vocante de la técnica moderna no corresponde al confiar, Heidegger nos pide confiar en el destino, hasta el punto de identificar "lo confiador" con "lo salvador". Es este último que puede permitir al hombre intuir su dignidad que la entiende de manera peculiar:

Dignidad que consiste en custodiar el desvelamiento y con él el previo velamiento de todo ser sobre la Tierra. (Heidegger: 1993, 102).

El hombre como "pastor"custodia el desvelamiento y el velamiento de "todo ser", como diria un budista: ser la madre de todos los seres. Nada más lejos de la experiencia postmoderna de desbocamiento de la experiencia subjetiva, intuyendo quizá que por el eamino de la tecnociencia ya todo está perdido, por lo que hay que refugiarse en lo privado. Y esa misma actitud es posibilitada por la misma esencia de la técnica.

Así, en la esencia misma de la técnica se encuentra "el posible surgimiento de lo salvador". Si permanecemostembelesados-en la têcnica, ello impedirá la custodia conmemorativa. Sin émbargo,jaedsénciandedactéenica es ambigua: por un lado, lo dis-puesto como esencia "disloca toda mirada para el acontecimiento del ocultamiento", es decir, pone en peligro nuestra unión con la esencia de la verdad. Por otro lado, dado que lo dis-puesto es posible por lo acordado y confiador, permitiendo al hombre la custodia de la esencia de la verdad. Permitiendo así el surgimiento de lo salvador. Esta ambigua esencia de la técnica es "la marcha estelar de lo misterioso", es decir, de la verdad. Así, por un lado vemos el peligro, por otro vemos el crecimiento de lo salvador. Pero añade Heidegger:

Con eso no estamos ya salvados. Pero estamos reclamados a esperar en la creciente luz de lo salvador. ¿Cómo puede acontecer esto? Aquí y ahora y en lo humilde, de tal manera que cuidemos lo salvador en su crecimiento. Esto implica que mantengamos siempre ante la vista el peligro más extremado. (Heidegger: 1993, 104). 
Ahí está la tarea del pensador: cuidar lo salvador y estar alertas ante el peligro más extremo. Ante el misterio de la verdad y de nosotros mismos, permanecer alertas y vigilantes como dicen los evangelios.

\section{Técnica y arte}

La esencia de la técnica amenaza a la verdad, y que ésta pase a ser identificada con el desvelamiento de lo constante. Y aunque el hacer humano por si sólo no puede enfrentar ese peligro, puede meditar en lo salvador como "esencia más elevada", que Heidegger la entiende como un "desocultar más primigenio". Es aquí donde vuelve a ampliar el sentido griego de lo técnico que, según él, también era el "pro-ducir de lo verdadero en lo bello", es decir, el arte.

Heidegger sostiene que las artes no fueron un sector de la producción cultural ni fueron gozadas estéticamente. El arte estaba relacionado en primer lugar con la verdad, con el desocultar que pro-duce la verdad en lo que aparece. Por eso es que poiesis hace referencia también a lo poético, a la poesía. Aunque nuestro pensador no está seguro que el arte esté confiado proteger el crecimiento de lo salvador. Sin embargo, añade:

Porque la esencia de la técrica no es nada técnico, la reflexión sobre la técnica y la contraposición decisiva con ella, tiene que tener lugar en un ámbito que, poRunllado,estâ emparentadecondaesencia de la técnica y que, de otro, es, singembargo, furidamentalmente distinto. Tal ámbito es el arte. (Heidegger: 1993, 107).

El arte, emparentado y fundamentalmente distinto de la esencia de la técnica, un ámbito en el cual el hombre pude encontrar una superación del pensar técnico. Pero la condición es que la reflexión artística no se cierre a la constelación de la verdad, es decir, que no cometa el mismo error de la tecnociencia: creer que es la única forma válida de verdad. Heidegger, pues, aboga por una meditación sobre la esencia de la técnica, la cual volverá misteriosa la esencia del arte. Heidegger termina su obra sosteniendo que cuanto más preguntadores nos volveremos, pues "el preguntar es la devoción del pensar". 


\section{BIBLIOGRAFIA}

BERCIANO, Modesto. Técnica moderna y formas de pensamiento. Salamanca: Universidad de Salamanca. 1982.

HEIDEGGER, Martin. Carta sobre el humanismo. Madrid: Taurus. 1970.

. "La pregunta por la técnica", en Ciencia y técnica. Santiago de Chile: Editorial Universitaria, 1993.

. El ser y el tiempo. México: Fondo de Cultura Económica, 1962.

. Introducción a “¿Qué es metafísica”, en Hitos. Madrid: Alianza Edito rial, 2001.

. "La época de la imagen del mundo" en Sendas perdidas. Buenos Aires: Losada, 1960.

MOYA, Eugenio. Crítica de lârazón lecnocientifica. Madrid: Biblioteca Nueva. 1998.

\section{Biblioteca de Letras "Jorge Puccinelli Converso"}

